\title{
ON GRONWALL-BELLMAN-BIHARI TYPE INTEGRAL INEQUALITIES IN SEVERAL VARIABLES WITH RETARDATION FOR DISCONTINUOUS FUNCTIONS
}

\author{
G. IOVANE
}

Abstract. In this work some new nonlinear inequalities of the Gronwall-Bellman-Bihari type in n-independent variables with delay for discontinuous functions are presented. They have nonLipschitz type discontinuities in some set of points for a n-dimensional Euclidean space. The results $r$ extend recent results of R. Bellman, I. Bihari, B. K. Bondge, V. Lakshmikantham, B. G. Pachpatte for continuous case of integral inequalities and its generalization for integro-sum inequalities (discontinuous case) presented in the investigations of D. Bainov, S. Borysenko, V. Lakshmikantham, S. Leela, A. Samoilenko.

Mathematics subject classification (2000): 26D15, 26D20.

Key words and phrases: integral inequalities, discontinuous functions, estimates, impulsive differential equations, retardation.

\section{REFERENCES}

[1] R. P. Agarwal, On an integral inequality in n-independent variables, J. Math. Anal. Appl., 85, (1982), 192-196.

[2] R. P. Agarwal, Difference Equations and Inequalities: Theory, Method and Applications, New-York, 1992.

[3] O. AKINYELE, On Gronwall-Bellman-Bihari type integral inequalities in several variables with retardation, J. Math. Anal. Appl., 104, (1984), 1-24.

[4] D. Bainov, P. Simeonov, Integral Inequalities and Applications, Kluwer Academic Publishers, Dordrecht, 1992.

[5] E. F. BeChenBaCH, R. Bellman, Inequalities, Springer-Verlang, 1961.

[6] P. R. BEESACK, On some Gronwall-type integral inequalities in $n$ independent variables, Journal. Math. Anal. Appl., 100, (1984), 393-408.

[7] R. Bellman, K. L. CoOKe, Differential-Differences Equations, Academic Press, New-York, 1963.

[8] I. BIHARI, A generalization of a lemma of Bellman and its application to uniqueness problems of differential equations, Acta. Math. Acad. Sci. Hungar., 7, (1965), 81-94.

[9] B. K. Bondge, B. G. PAChPATte, On some fundamental integral inequalities in two independent variables, J. Math. Anal. Appl., 72, (1979), 533-544.

[10] B. K. BondGe, B. G. PACHPATTE, On Wendroff type integral inequalities in $n$-independent variables, Chinese J. Math., 7, (1979), 37-46.

[11] D. S. BorysenKo, About one integral inequality for piece-wise continuous functions, Proc. X Int. Kravchak Conf., Kyiv, (2004), 323.

[12] S. D. BORYSENKO, Study in solution stability and attraction of the system of differential equations with impulse excitation, Preprint N.82-35, AS Ukr SSR. Inst. Matematiki, Kiev, 1982.

[13] S. D. BORYSENKO, Integro-sum inequalities for functions of many independent variables, Differential Equations, 25, (9) (1989), 1638-1641.

[14] S. D. BorYSEnKo, Construction of Mathematical Models, Vipol, Kiev, 1995.

[15] S. D. Borysenko, G. IovAne, Integro-Sum Inequalities and Qualitative Analysis Dynamical Systems with Perturbations, (Ed. by Yu. A. Mitropolskiy), Tipogr. Legat. Elda, Univ. of Salerno, Salerno, 2006. 
[16] A. N. Filatov, L. V. Sharova, Integral Inequalities and Theory of Nonlinear Oscillations, Nauka, Moscow, 1976.

[17] T. H. GRONWALL, Note on the derivatives with respect to a parameter of the solutions of a system of differential equations, Ann. Math., 20, (2), (1919), 292-296.

[18] V. LaKshmikantham, S. Leela, Differential and Integral Inequalities. Theory and applications, Academic Press, New-York, 1969.

[19] V. Lakshmikantham, D. Trigiante, Theory of Difference Equations and Numerical Analysis, Academic Press, New-York, 1987.

[20] V. LAKShmikANTHam, D. D. Bainov AND P. S. SimeOnov, Theory of Impulsive Differential Equations, Series in Modern Applied Mathematics, 6, (1989).

[21] A. A. MartyhyuK, V. LaKshmikantham and S. Leela, Stability of Motion: The Method of Integral Inequalities, Nauk. Dumka, Kiev, 1989.

[22] Yu. A. Mitropolskiy, S. LeEla And A. A MartynyuK, On some trends of V.Lakshmikantham's investigations in the theory of differential equations and their application, Different. Equat., 4, (22) (1986), 555-572.

[23] YU. A. MitropolskiY, S. BORYSENKO AND G. IOVANE, About a generalization of Bellman-Bihari type inequalities for discontinuous functions and their applications, Preprint n. 8, DIIMA University of Salerno, Salerno, 2006.

[24] B. G. PACHPATTE, Inqualities for Differential and Integral Equations, Academic Press, New-York, 1998.

[25] A. M. SAMOILENKo, S. D. BorysENKo, On fuctional inequalities of Bihari type for discontinuous functions, Uspehi Mat. Nauk., 53, (4) (1998), 147-148.

[26] A. M. Samoilenko, S. D. Borysenko, C. Cattani and G. Matarazzo, V. Yasinsky, Differential Models: Stability, Inequalities and Estimates, Naukova Dumka, Kyiv, 2001.

[27] A. M. SAMOILENKO, N. PERESTYUK, Stability of solutions of differential equations with impulsive effect, Differ. Equat., 13, (1) (1977), 1981-1992.

[28] M. H. SHIH, C. C. YeH, Some integral inequalities in $n-$ independent variables, J. Math. Anal. Appl., 84, (1981), 569-583.

[29] E. Thandapani, R. P. Agarwall, On some new inequalities in $n-$ independent variables, J. Math. Anal. Appl., 86, (1982), 542-561.

[30] W. WALTER, Differential and Integral Inequalities, Springer-Verlag, New York, 1970.

[31] C. C. YeH, Bellman-Bihari inequalities in several variables, J. Math., Anal. Appl., 87, (1982), 311-321.

[32] E. C. YounG, Gronwall's inequality in $n$-independent variables, Proc. Amer. Math. Soc., 41, (1973), 241-244.

[33] A. I. Zahariev, D. D. Bainov, A note on Bellman-Gronwall's inequality, J. Math. Anal. Appl., 80, (1981), 147-149. 